RESEARCH REPORT

\title{
Framing pub smoking bans: an analysis of Australian print news media coverage, March 1996-March 2003
}

\author{
David Champion, Simon Chapman
}

J Epidemiol Community Health 2005;59:679-684. doi: 10.1136/jech.2005.035915

See end of article for authors' affiliations

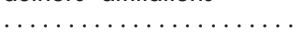

Correspondence to: Professor S Chapman, School of Public Health, University of Sydney,

Australia;

simonchapman@health. usyd.edu.au

Accepted for publication 3 June 2005

\begin{abstract}
Objective: To investigate framing strategies used by the Australian Hotels Association (AHA) and tobacco control groups to (respectively) resist or advocate laws providing smoke free bars.

Methods: Online archives of Australian print media were searched 1996 to 2003. A thematic analysis of all statements made by AHA spokespeople and tobacco control advocates was conducted. Direct quotes or journalistic summaries of statements attributed to named people were coded into four broad themes and the slant of articles coded.

Results: More than three times as many articles reported issues that were positive $(n=171)$ than negative $(n=48)$ for tobacco control objectives. The AHA emphasised negative economic issues and cultural/ ideological frames about cultural identity, while tobacco control interests emphasised health concerns as well as cultural/ideological frames about threats to inequitable workplace policies.

Conclusions: Smoke free bars have now been secured, suggesting that health advocates' position prevailed. The inability of the AHA to avoid the core health arguments, its wildly exaggerated economic predictions, and its frequent recourse to claiming smoke bans threatened nostalgic but outmoded vistas of Australian day to day life were decidedly backward looking and comparatively easily dismissed as being out of touch with views held by many in contemporary Australia. Health groups' emphasis on the unfairness in denying the most occupationally exposed group the same protection that all other workers enjoyed under law was powerfully and consistently argued. Australia's recent success in securing dates for the implementation of smoke free pubs is likely to have owed much to the enduring media advocacy by health groups.
\end{abstract}

n Australia today, laws require that all halls, theatres and cinemas, public transport, aircraft, airport interiors, elevators, and indoor areas of restaurants be free from tobacco smoke. Occupational health and safety legislation has ensured that indoor workplaces are also smoke free, including tobacco company offices. ${ }^{1}$ These restrictions started in the 1970s with legislation tackling fire risks. With the growth of research on the health effects of exposure to environmental tobacco smoke (ETS), from the mid-1980s Australian governments began to introduce legislation explicitly grounded in concerns to protect non-smokers from ETS.

Public opinion supporting smoke free legislation has grown in this time ${ }^{2}$ as has the proportion of homes where residents report not permitting smoking indoors. ${ }^{3}$ Six weeks before the 2000 Sydney Olympic Games, the New South Wales government banned smoking in the indoor sections of restaurants. ${ }^{4}$ Today, all states and territories have similar legislation. Bars, clubs, and gaming rooms now remain the last significant enclosed public places where patrons are free to smoke and staff are unprotected by law. Recent announcements from all Australian states have set dates, starting in January 2006 in Tasmania when all bars will be smoke free (see http://tobacco.health.usyd.edu.au/site/supersite/resources/pdfs/ pubs_smokefree.pdf for a timetable).

This pattern of incremental restrictions on smoking whereby pubs remain, often for years, the "last bastion" for smoking is typical in the many nations where smoking is now restricted. California, New York, Ireland, and Italy are four of the most publicised places where bars are now also smoke free, and each has experienced protracted and often acrimonious public debate between those advocating for smoke free bars and those determined to preserve smoking in the hospitality industry. ${ }^{5-7}$
With bar ETS exposures being among the most heavy, ${ }^{8}$ high priority has been given by health groups to efforts at convincing governments to act. ETS has remained the leading topic covered in news reportage of smoking ${ }^{9}{ }^{10}$ since the late 1980s. In the early days of this advocacy, the tobacco industry was the principal opposing public voice, but in recent years the industry has played an increasingly subdued public part, with third party groups with funding connections to the tobacco industry" taking the "front line" roles in public debate. The most prominent of these has been the Australian Hotels Association (AHA), the principal trade association of the hotel industry in Australia. The AHA is prominent in debates about alcohol, gambling, and ETS. Its web site notes that one of its functions is to maintain and develop media relationships to ensure that the media is [sic] aware of key issues of importance to the hospitality industry." ${ }^{12}$ The AHA has received direct support from the tobacco industry to oppose smoking bans. ${ }^{13} 14$

This paper is a case study of all public statements in the Australian print media between 1996 and 2003 made by the AHA to oppose smoke free legislation in bars. Specifically, it examines differences between statements attributed to AHA spokespeople and those attributed to smoke free advocates such as the Heart Foundation, Quit, Action on Smoking and Health, and the medical community.

Statements attributed to those reported in the press ("news actors") are selected by journalists from press releases issued by those hoping to influence news coverage and from interviews with these informants. The demands of space and brevity in news reportage necessarily entail journalistic selection, so that quotes selected for inclusion

Abbreviations: AHA, Australian Hotels Association; ETS, environmental tobacco smoke 
always represent statements deemed to best characterise elements perceived by the journalist to be what a story is "about".

\section{FRAMING}

Skilled advocates try to work within the constraints required of journalists and strategically emphasise concerns they hope will define the dominant frame of meaning around an issue and the one that key decision makers will come to share. To frame is to "select some aspects of a perceived reality and make them more salient... in such a way as to promote a particular problem definition, causal interpretation, moral evaluation and/or treatment recommendation". ${ }^{15}$ In this way news media play a critical part in defining what is at issue in public debates and can often be highly influential in shaping policy decisions. ${ }^{16}$ Frames not only define what problems are seen as being important, but also their causes and preferred solutions.

Those who oppose bans on smoking in bars and clubs in Australia succeeded in holding back for well over a decade what many politicians ${ }^{17}$ and even opponents ${ }^{18}$ finally began to call an "inevitable" decision. Research illuminating the qualities of ban opponents' discourse and its differences with that advanced by advocates for smoke free bars may prove useful in increasing understanding among public health advocates about frames that appear to resonate more with political decision makers. In examining the pattern of this discourse and its main frames across eight years, greater understanding may be developed of how the endgame of protecting workers and the public from ETS plays out in public debate. Our discussion addresses possible lessons for public health advocates seeking to advocate their concerns more effectively.

A growing number of studies have examined the reporting of tobacco issues in the news, including reportage about ETS. ${ }^{19}{ }^{20}$ Magzamen et al identified themes such as "restricting freedom of choice" and "economic ramifications" used by the US tobacco industry to oppose smoking restrictions. ${ }^{21}$ The only comparable analysis of framing tactics over time concluded that while the tobacco industry has created a central message and theme that has been used constructively and consistently over time, the tobacco control movement has not developed a consistent, powerful, and compelling message. $^{22}$

\section{METHODS}

Using the search string "tobacco or smoking" and "AHA or Australian Hotels Association" the Nexus Lexus online archive of Australian metropolitan print media was searched for all items published between 25 March 1996 and 3 March 2003. After excluding articles that did not refer to the debate about smoking in the hospitality industry, 262 articles were located of which 34 were opinion articles or letters to the editor. Both broadsheets, (quality papers), and tabloids (popular newspapers) were included. The articles were reviewed and their publication, date, type of article, headline, and slant on smoke free bars were recorded.

The slant of an article was defined from the perspective of a tobacco control advocate. If the headline and lead paragraph were deemed generally favourable to tobacco control objectives, the slant was recorded as positive. If the headline and lead paragraph were judged as unfavourable to the introduction of smoke free public hospitality environments, the article was coded negative. Those not clearly favouring either side of the debate were coded neutral/balanced. Particular attention was paid to the headline and the lead paragraph because these areas act to anchor the meaning of articles, contain the story's main trajectory, and encapsulate what the journalist and subeditor consider to be the most important, newsworthy

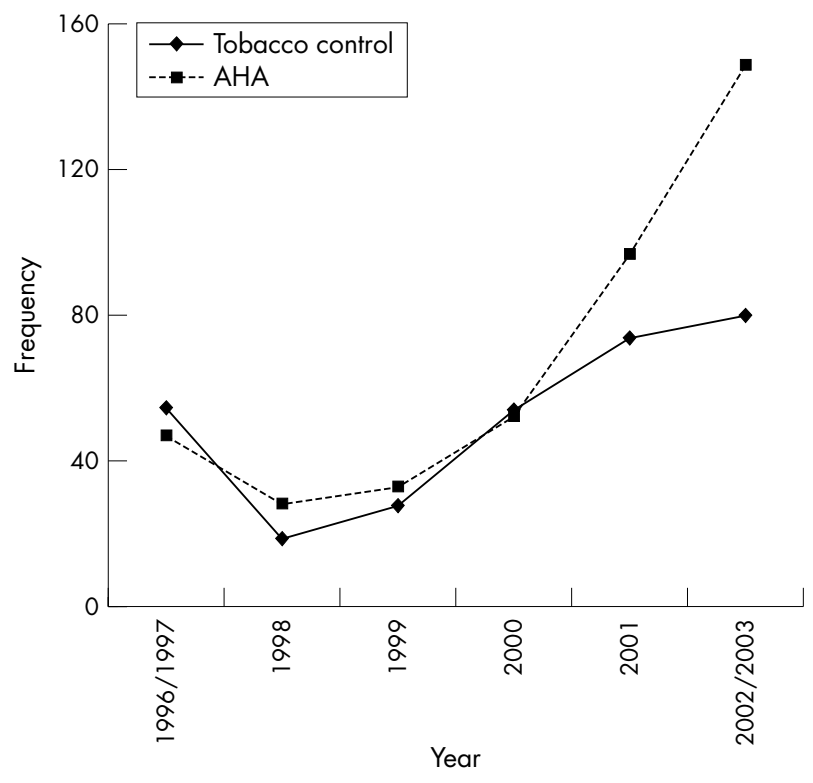

Figure 1 Frequency of AHA and tobacco control quotes. Data for the full year 1996 were unavailable due to database limitations. The frequency of statements from March 1996 to 1997 are shown together. The Nexus Lexus database was accessed on 3 March 2003. Consequently, the frequency of statements representing the year 1 January 2002 to 3 March 2003 are shown together.

or interesting aspect. ${ }^{23} 24$ If the slant of the headline was considered different from that of the lead paragraph then the article slant was determined from the lead paragraph.

Examples of positive, negative, and neutral slant were:

- Positive headline: "Smoking bans do not damage pub trade".

- Positive lead paragraph: "Smoking bans in restaurants and bars do not lead to a loss of revenue or jobs, and may even improve patronage, according to research".

- Negative headline: "Job losses blamed on smoke ban".

- Negative lead paragraph: "Smoking bans at Crown Casino have been blamed for the shock axing of more than 100 jobs".

- Neutral headline: "Mixed smoke signals from the bars".

- Neutral lead paragraph: "There was a mixed response from publicans, patrons and industry groups as Tasmania's new smoking legislation came into effect yesterday".

All direct quotes or journalistic summaries of statements attributed to named individuals in each article were then coded. Coding was initially narrow and precise, with the number of categories reaching 57 as coding proceeded. These 57 categories were then reduced to four broad content areas that appeared to admit all instances with the exception of a residual "general" category. The final five themes were health, economic, cultural/ideological, practical, and general, which were defined as follows:

\section{Health}

Statements about heath issues and ETS exposure regarding patrons or staff, including statements both asserting and denying or playing down the connection between exposure and health risks.

\section{Economic}

Statements about the economic consequences of introducing smoke free hospitality venues, suggesting positive, negative or neutral consequences. 


\section{Cultural/ideological}

Statements about public support or opposition to smoke free bars; non-smokers' and smokers' "rights"; that bar workers' occupational health status was being neglected; that bans are "unAustralian"; that bans constitute "prohibition" or overly bureaucratic interference in the conduct of business; that the issue is "political"; that policy should be left to individual venue management via self regulation; and statements about legal liability and discrimination.

\section{Practical}

Statements about the practicalities of implementing smoke free bars; the futility of arbitrary smoking and non-smoking zones; comments about the adequacy or inadequacy of ventilation solutions; and ban timing matters.

\section{General}

Statements containing no value laden comments of support or opposition to smoke free bars were coded "general". Examples included an AHA statement that they were "surprised to hear [the government] was flagging wider bans" and statements from health advocates clarifying how, when or where smoking legislation would be implemented.

\section{RESULTS}

From the 262 eligible articles retrieved 712 distinct quotes attributed to either AHA spokespeople $(n=413)$ or tobacco control advocates $(\mathrm{n}=299)$ were identified (table 1$)$. The rise in AHA quotes paralleled the increase in articles published during this time. From 1996 to 1999, there was an average of 21 articles published every year. By 2001 and 2002 this had increased more than threefold to 73 per year. Those attributed to AHA spokespeople grew continuously from 1998, with sharp growth from 2000 onward, after the "fall" of restaurants to smoke free status that gained momentum from 2000 with the announcement of a ban in New South Wales (fig 1). When restaurants went smoke free, the debate predictably shifted entirely onto hotels and clubs, where the AHA had an obvious vested interest. By 2002, the AHA was being quoted at twice the rate of tobacco control advocates, suggesting aggressive advocacy by the AHA. In May 2001, there was intense press coverage of the Marlene Sharp legal case in Australia, in which a court found that a non-smoking, near teetotal bar worker's throat cancer was caused by exposure to ETS. ${ }^{25}$

Despite the preponderance of AHA quotes, across the full sample period there were more than three times as many articles reporting on the issue that were positive $(n=171)$ than were negative for tobacco control $(n=48)$. These positively slanted articles highlighted the merits of tougher smoking bans, efforts to include gaming areas in smoking bans, and reports on studies showing that smoking bans did not harm business. Negatively slanted articles tended to highlight claims that smoking bans would destroy a bar tradition, cut earnings, cause job losses and presented a spectre of unfairly besieged hotels fighting back.
Table 1 shows the distribution of statements made by AHA and tobacco control spokespeople. The AHA consistently emphasised economic issues $(40 \%$ of all their attributed quotes) and cultural/ideological frames (36.3\%), while tobacco control interests emphasised health concerns (32.4\% of all their quotes, while virtually absent from AHA statements-only 10 of 413 statements) as well as cultural/ ideological frames $(42.1 \%)$. Practical concerns were expressed three times more often by the AHA than by tobacco control groups, but much less than the dominant economic, cultural/ ideological discourses favoured by the AHA. Each of the four main themes (health, economic, cultural/ideological, and practical) will now be explored in greater detail.

\section{Health framing}

Statements on health came overwhelmingly (nine to one) from health groups, with the AHA remaining largely silent on health issues, being quoted only 10 times. The right of hospitality staff to work in a smoke free environment, irrespective of the willingness of some to work in smoky environments, and the unacceptable "exceptionalism" that gave protection to all workers except bar staff was the core frame used by health groups. Health groups and labour unions representing hospitality workers appropriated the "last bastion" debating frame first used by opponents of bans, and argued that "the hospitality industry is the last bastion where workers have to suffer someone else's smoke", that "all other workers are being protected at their place of work", and that "no employee should be forced to work in conditions where they are in constant contact with a known carcinogen". Health groups highlighted research showing hospitality workers were the group most exposed to ETS.

On the few occasions the AHA was quoted on health it mainly denied the risks involved saying it had made use of "specialist medical advice, giving the all-clear for adults exposed at work" and that "evidence in relation to passive smoking and adverse health effects remained weak and inconclusive".

By 2000 the AHA began to acknowledge the risks associated with ETS and stated that they "had always taken its health responsibilities to staff and patrons extremely seriously" but defended their position by claiming that they make "all employees aware of the risks in their initial orientation", and that hotels were now making every effort in "educating staff about the risks". Some hoteliers reported that they had made it a "condition of employment for nonsmoking staff to sign a waiver acknowledging they understood and accepted the risks of passive smoking", a strategy that would have been legally vulnerable if challenged in court. The waiver, they reported "was protection against legal action".

\section{Economic framing}

The second most frequent framing used in the debate was economic, with the AHA making economic statements 3.5 times more often than health groups. The AHA consistently warned of "horrendous ramifications" and "certain

Table 1 Frequency of frames used by tobacco control groups and the AHA, quotes (\%)

\begin{tabular}{llll}
\hline & Tobacco control & AHA & Total \\
\hline Health & $97(32.4)$ & $10(2.4)$ & $107(15.0)$ \\
Economic & $47(15.7)$ & $165(40.0)$ & $212(29.8)$ \\
Practical & $21(7.0)$ & $64(9.0)$ & $85(11.9)$ \\
Cultural/ideological/legal & $126(42.1)$ & $150(36.3)$ & $276(38.8)$ \\
Miscellaneous/general & $8(2.7)$ & $24(3.4)$ & $32(4.5)$ \\
Total & 299 & 413 & 712 \\
\hline
\end{tabular}


bankruptcy" for many small pubs particularly in country towns that "could not afford to install the necessary ventilation equipment". Ventilation solutions were never part of what was being proposed by health groups, so the AHA tactic here was to both propose an alternative (bogus) solution while emphatically claiming it would be financially ruinous for many hotels. The AHA constantly promoted the spectre that "business will decrease". Smoking bans had "the potential to kill off a number of small country pubs which rely purely on their bar sales" and that smoke bans would be "devastating for hotels" because "if you took the smoking out then you'd be closing the door". There were numerous predictions of "catastrophic consequences" and that "the cost to society would be immense". This apocalypse would cause "major flow-on effects including higher land taxes and increases in car regos [registration]" that would reduce the ability of the government to provide police and health education programmes.

In particular the AHA warned of the loss of "thousands of jobs" and referred to domestic and international experience to support their claims: "in Boston they laid off three people in every bar and cafe" and "in California about one in five surveyed respondents said they had laid off staff". It claimed that $13 \%$ of Californian bar jobs disappeared after antismoking laws were introduced and that similar employment repercussions would happen in Australia. The AHA "said the revenue decline would cost up to 3000 full-time jobs" and that in casinos, smoking restrictions had already "been blamed for the shock axing of more than 100 jobs". The bans would "be a blow to the tourist trade" and "if you're going to introduce cultural change, you have to be a little bit sensitive to that other very important culture we like-jobs".

Health groups countered these arguments by claiming US evidence showed smoking bans could improve patronage. They noted that the AHA was using similar predictions of disaster that it "had used for more than 20 years" that random breath testing would also empty hotels and cause job loses. They argued that the AHA was only interested in money, claiming that the economic arguments were "like the scene in Jaws when people are saying 'you've got to close the beach' and they won't because it's tourist time and people are making money".

\section{Cultural/ideological/legal framing}

From the entire sample of quotes, core cultural or ideological statements were the most frequent (39\%). The AHA consistently maintained that smoking was a core part of Australian culture and almost an historical birthright: "going to the bar and having a beer and a smoke is part of our culture", "people have been smoking in Australia since they [Captain James Cook] landed here at Botany Bay"; "any type of ban affects our culture" and that further bans would discriminate against individuals' rights. They maintained that while it was "fashionable to be against smokers" a "complete ban on smoking in bars was taking things too far, we would be turning smokers into lepers". Health groups and politicians were engaging in "cultural engineering" and "while statistics showed only 20.3\% of Australian adults smoked, a total ban on smoking was discriminatory and unAustralian" and that "smoking in the pub is the Australian way" because "people can't enjoy a beer if they don't have a smoke".

The AHA questioned the need to legislate against smoking, arguing that self regulation had been working. "Under selfregulation, hoteliers were attending seminars and installing air filters". This, the AHA argued, "was a much more sensible means of handling smoking". "Many hotels also introduced smoking and non-smoking areas many years ago and to introduce an outright ban now will alienate people".
The AHA argued that tobacco is a legal product and so we cannot alienate those who choose to use it because "the majority of smokers are very considerate". If it was legal to buy cigarettes in hotels it should be legal to smoke them inside hotels.

Finally, the AHA invoked populist antipathy for prohibition, arguing that "it is merely prohibition and history tells us prohibition doesn't work". They argued bans were no more than "red tape which pacifies the crusaders but achieves little else".

Health groups mixed health framings with ideological angles, maintaining that while patrons choose whether to go to smoke filled pubs, the argument that bar staff have the same choice was "redolent of Dickensian mine owners asserting that they didn't force 10-year-olds down mines: they could always get another job." They also highlighted the threat of the legal consequences if smoking were allowed to continue. They argued that "employers knew the risks to patrons and employees" and that the AHA were "leaving themselves open to potentially huge legal claims" that would result in "huge ramifications" for the hospitality industry. Tobacco control groups argued that the AHA were under legal responsibility to protect workers: "we've clearly warned employers that they're accruing a legal liability for those who will inevitably suffer illness or death from unsafe work environments". They argued that insurance companies will inevitably say that "if you want workers compensation insurance, then make your establishment smoke-free". Health groups compared passive smoke with asbestos, suggesting "where the danger is known, it's quite clear that employers can be in breach of legal obligations where they've failed to act" and "if they want to lift the threat of legal liability which hangs over their heads [pubs and clubs] will need to go totally smoke-free".

Some health groups claimed that the government "showed a lack of political courage" and that the "onus was on governments to protect workers, as the hotel industry has been blocking smoking bans and lobbying governments to delay actions for nearly a decade". Politicians were seldom quoted but also acknowledged that more restrictions in pubs and clubs were inevitable. Other politicians down played the issue saying "a total ban was an option, albeit an unlikely one, but that the Government wanted feedback from pubs and clubs before making any decision". They signalled there could be "further advances in legislation but said the Government would not react in a knee-jerk way" while other government ministers were quoted as saying they "remained committed to achieving smoking bans in hotels in the future".

\section{Practical framing}

In 1996 the AHA argued that dispersing smoke with fans, exhaust systems, open windows, and air grilles was the practical solution to heightened public concern about secondhand smoke. Further legislation would now be impractical as the hotel industry "was aware of the passive smoking issues and could do numerous things to improve air

\section{What this paper adds}

Proposals to ban smoking in bars and pubs attract prolonged and heated debate from vested interest groups concerned to maximise smoking opportunities. Systematic analysis of the main frames used in these debates can assist in advocacy. This paper reviews four principal areas of debate that occurred in Australia between 1996 and 2003 and suggests why the proponents of smoke free bars eventually prevailed. 
circulation to reduce the problem". The AHA claimed it was now "policy to encourage hotel owners to install 'state-ofthe-art ventilation systems"'.

Health groups countered the ventilation solution by arguing that "even the best ventilation systems do not clear the air completely" and that "they do not protect workers from the health problem and do not protect hotels and restaurants from being sued by workers or patrons". The Australian Medical Association wrote that it "had received scientific advice that to remove cancer-causing particles from the air that the air-conditioning would have to be so powerful it would suck the beer out of your glass". Health groups argued that sections divided by an arbitrary line was analogous to having a urinating and non-urinating section in a swimming pool.

\section{DISCUSSION}

Public health advocates campaign about ETS because it is a preventable health issue that can readily be tackled through legislation. The hospitality industry has campaigned against their efforts because they claim smoking restrictions will deter patrons and because of a myopic belief that part of the atmosphere of bars is that unhindered smoking is a "natural" companion to drinking. The endgame of the history of restricting public smoking is essentially a struggle for ascendancy between these two fundamentally different conceptions about what is at issue in the contested debate about bar smoking.

Now that health groups' concerns have prevailed with announcements by all Australian state governments that smoking inside bars will be banned starting in January 2006, it is reasonable to reflect on both why the debate took as long as it did to reach its conclusion, and why the health led argument eventually triumphed. This discussion must be unavoidably speculative because there is no "official" or definitive answer to either question, no person or group of people whose judgement on these questions could be considered inviolable and no moment when the decision was made, referenced against a particular incident or other critical event. Bryan-Jones has explored at length the political dynamics of the evolution of laws against public smoking in the state of New South Wales and her findings support this complexity. ${ }^{26}$

The dominant patterns of news discourse mapped in this study suggest three fundamental oppositions that jousted for ascendancy. Firstly, the health of workers and the public was pitted against the commercialism of the hotel industry. Secondly, two radically different appropriations of what it allegedly meant to be "Australian" became contested. Thirdly, debate about practical matters pitted those who worked in bars every day with those who could be painted as having little credibility when it came to the practical administration of a hotel or pub.

\section{Policy implications}

Proposals to eliminate smoking from indoor hospitality industry venues will be heavily contested by the hospitality and tobacco industries. Advocates for smoke free bars and pubs need to anticipate the general and specific debating frames they will face in seeking to meet their case, and rehearse counteracting debating frames and arguments that they will meet in these conflicts if they are to best represent public health objectives.

\section{Health compared with commercialism}

In this study, health advocates were most often quoted via comments about the health problems of passive smoking, while the AHA almost totally avoided any engagement with health matters. As authorities and advocates on health matters, health groups are contacted by journalists as sources who are expected to provide a health perspective. While the tobacco industry has a long history of attacking the evidence about the harms caused by secondhand smoke ${ }^{27} 28$ it also recognised that "The tobacco industry is still attempting to win an unwinnable argument ... namely that there is a valid scientific controversy concerning smoking and health issues". ${ }^{29}$ It thus enlisted third parties such as hospitality associations to fight smoking restrictions. ${ }^{5}$

The AHA largely kept away from the health agenda and sought to frame what was at issue via other agenda. This absence gave health groups years of almost uncontested opportunities to raise the core health issues. As new research continued to be published and publicised, the absence of government response to ever growing evidence of harm became less and less politically sustainable, and the word "inevitable" began to be used by politicians to refer to bans. Either explicitly or by implication, the health perspective remained the core, unavoidable starting point of every media report about ETS.

\section{Ways to be "unAustralian"}

As we saw, the AHA dug deep into a store of references about cultural heritage in the attempt to frame smoking bans as antithetical to quintessentially Australian tableaux about authentic day to day life. Here, references to country town pubs and men who would be denied a smoke with their beer after a hard day's work. One taunted smoking ban advocates to go to the "Royal Hotel in Coonabarabran [a quintessential country town] in the middle of a drought, bushfires and hardship, and tell the old man at the bar he's not allowed to smoke with his beer. I'm not going to do it. They've been doing this for years". Those proposing bans were by implication people who were out of touch with ordinary Australian values, who were employed in occupations that were not really "proper" jobs, and so whose advocacy needed to be placed in those perspectives and seen as a minority opinion seeking to be imposed on the community. If there was a weakness in this powerful set of interlinked frames, it was that the references and word pictures invoked in its support were decidedly backward looking and comparatively easily dismissed as being out of touch with world views held by many people in contemporary Australia. Restaurants had gone smoke free in 2000 to widespread acclaim and with few if any major problems ${ }^{30}$ and with public opinion overwhelmingly in favour of smoke free pubs, ${ }^{32}$ it is probable that many exposed to the AHA framing here would have found it out of date.

By contrast, health groups' take on being "unAustralian" was to bracket their health messages with ideological statements about fairness and it being manifestly inequitable and indefensible to deny the most occupationally exposed group the same protection that all other workers enjoyed under law. Being "unAustralian" is common parlance for behaviour or policies that are not egalitarian. Health groups reframed the AHA's "last bastion" status of hotels and bars as a neo-Dickensian irrational application of public health policy and were never directly challenged.

\section{Practical matters}

Being the owners and managers of pubs, it might be expected that the AHA would have a decided advantage over health advocates when it came to public argument about the practicalities of implementing smoking bans. They worked 
in these environments every day, whereas health group spokespeople could be readily painted as people who rarely ventured into pubs and so whose idealism and impracticality could be questioned. The AHA rapidly moved to embrace separate accommodation (sometimes defined by farcical "magic line" rules) and ventilation-especially air conditioning-as their solutions of choice.

However, both of these solutions were vulnerable to ridicule and imagery about high powered, uncomfortable, and expensive air conditioning systems that would be financially beyond the reach of small bars and evoked scenes of draughty, uncomfortable environments.

Our findings are consistent with those of Magzamen et al ${ }^{21}$ who concluded that the tobacco industry in the USA created an effective central message that has been used consistently over time. They showed that by consistently delivering well thought out framing strategies, public health groups can be effective in obtaining adequate attention to their arguments in the media, which were able to help them in maintaining smoke free environments in California's bars. Australia's recent success in securing dates for the implementation of smoke free pubs is similarly likely to have owed much to the enduring media advocacy by health groups.

\section{Study limitations}

Or study focused entirely on coverage of the pub smoking ban in newspapers. While newspaper coverage is usually highly correlated coverage in electronic news media ${ }^{33}$ it plainly underestimates total exposure. Also, our search strategy gathered only articles where the AHA was quoted. It is probable that there were many other articles relevant to smoking in pubs where the AHA was not quoted, particularly those where licensed club representatives-another important lobby group opposing smoke free venues-were quoted. Our study therefore provides a conservative view of the total media coverage of the extant issues.

\section{Authors' affiliations \\ D Champion, S Chapman, School of Public Health, University of Sydney, Australia}

Funding: none.

Competing interests: S Chapman is on the board of Action on Smoking and Health and has advocated for smoke free bars

\section{REFERENCES}

1 Nixon S. No smoking on the job if you work at Philip Morris. Sydney Morning Herald 2002; Nov 3:3

2 Walsh R, Tzelepis F. Support for smoking restrictions in bars and gaming areas: review of Australian studies. Aust N Z J Pub Health 2003;27:310-22.

3 VicHealth Centre for Tobacco Control. National tobacco strategy 1999 to 2002-03 occasional paper: environmental tobacco smoke in Australia. http://www.health.gov.au/pubhlth/publicat/document/env_ets.pdf.

4 Bevan S. Smoking ban spreads. http://aca.ninemsn.com.av/stories/467.asp (accessed 17 Aug 2004)
5 Dearlove JV, Bialous SA, Glantz SA. Tobacco industry manipulation of the hospitality industry to maintain smoking in public places. Tob Control 2002;11:94-104

6 Clarke H, Wilson MP, Cummings KM, et al. The campaign to enact New York City's Smoke-Free Air Act. J Public Health Manag Pract 1999;5:1-13.

7 McElvaney NG. Smoking ban--made in Ireland, for home use and for export. N Engl J Med 2004;350:2231-3

8 Bates M, Fawcett J, Dickson S, et al. Exposure of hospitality workers to environmental tobacco smoke. Tob Control 2002;11:125-9.

9 Chapman S. The news on smoking: editorial coverage of tobacco and health issues in Australian newspapers, 1987-88. Am J Public Health 1989;79:1419-20.

10 Durrant R, Wakefield M, McLeod K, et al. Tobacco in the news: an analysis of newspaper coverage of tobacco issues in Australia, 2001. Tob Control 2003;12:75-81ii

11 Chapman S, Penman A. Can't stop the boy: Philip Morris' use of Healthy Buildings International to prevent workplace smoking bans. Tob Control 2003;12(suppl 3):iii107-12.

12 Australian Hotels Association NSW. http://www.aha-nsw.asn.au/ laccessed 16 Aug 2004)

13 Harper T, Martin J. Trojan horses: how the tobacco industry infiltrates the smokefree debate in Australia. Aust N Z J Public Health 2002;26:572-3.

14 Baxter P. Territory smokers face tough laws. Northern Territory News 2002;Apr 29:5.

15 Entman RM. Framing: toward clarification of a fractured paradigm. J Communication 1993;43:51-8.

16 Nelkin D. Selling science: how the press covers science and technology. 2nd ed. New York: W H Freeman, 1995.

17 King M. State election 2002; smoke-free gambling on the agenda. The Advertiser 2002; Jan 17:6.

18 Anon. Smoke-free dining areas inevitable. Illawarra Mercury 2000;May 4;6.

19 Kennedy GE, Bero LA. Print media coverage of research on passive smoking. Tob Control 1999;8:254-60.

20 Wakefield M, Clegg Smith K, Chapman S. Framing of news coverage about the Marlene Sharp legal judgement: a tipping point for smoke-free public places in Australia? Impacteen working paper, 28. http:// www.impacteen.org/ab RPNo28 2003.htm.

21 Magzamen S, Charlesworth A, Glantz SA. Print media coverage of California's smokefree bar law. Tob Control 2001;10:154-60.

22 Menashe C, Siegel $M$. The power of a frame: an analysis of newspaper coverage of tobacco issues-United States, 1985-1986. J Health Communication 1998:3:307-25.

23 van Diik TA. News as discourse. Hillsdale, NJ: L Erlbaum Associates, 1988.

24 Bell A. The language of news media. Oxford: Blackwell, 1991.

25 Stewart BW, Semmler PC. Sharp v Port Kembla RSL Club: establishing causation of laryngeal cancer by environmental tobacco smoke. Med J Aust 2002;176:113-16.

26 Bryan-Jones K. The political evolution of secondhand smoke legislation in New South Wales, Australia. MPhil Thesis, School of Public Health, University of Sydney. http://tobacco.health.usyd.edu.au/site/supersite/resources/ pdfs/bryan_jones_thesis_2004.pdf.

27 Drope J, Chapman S. Tobacco industry efforts at discrediting the science of environmental tobacco smoke: a review of internal industry documents. $J$ Epidemiol Community Health 2001;55:588-94.

28 Trotter L, Chapman S. Conclusions about exposure to ETS and health that will be unhelpful to us: how the tobacco industry attempted to delay and discredit the 1997 Australian National Health and Medical Research Council report on passive smoking. Tob Control 2003;12(suppl 3):iii102-6.

29 Davies D. Notes for presentation. http://legacy.library.ucsf.edu/tid/ chh29e00 (accessed 15 Jan 2005).

30 Chapman S, Borland R, Lal A. Has the ban on smoking in NSW restaurants worked? A comparison of restaurants in Sydney and Melbourne. Med J Aust $2001 ; 174: 512-15$

31 Reference withdrawn.

32 Community support for drug-related policy. http://www.aihw.gov.au/ publications/health/ndshs98qld/ndshs98qld-c04.pdf (accessed 7 Jul 2004).

33 Holder HD, Treno AJ. Media advocacy in community prevention: news as a means to advance policy change. Addiction 1997;92:S189-99.

34 Chapman S, Dominello A. A strategy for increasing news media coverage of tobacco and health in Australia. Health Promotion Int 2001;16:137-43. 